was visible in it. It is quite possible that the attacks may have been due to the exostosis which you have removed, especially if secretion had accumulated behind it; but time alone can decide this. The case puts me strongly in mind of one that I saw many years since. The attacks, one of which I witnessed, corresponded closely with the description given by $\mathrm{Mr}$. S. W- and the intellect was unimpaired to the last. The patient died in an attack, and on examination there was found tremendous thickening of the frontal bone. In any circumstances it was right to remove the exostosis and I shall be greatly interested in the result." The result was so far satisfactory that the hearing became quite restored in the ear operated on, and the patient, after a month's absence, went home apparently quite well. On the 29th of April Mr. Swannick wrote to me as follows:- "Since his return he has had a few fits, one of which, at evening service on Sunday, was severe. From that date till now I have been giving him bromide of potassium three times a day, and he has had only one slight attack. The gloominess and depression that come on every evening at about 7 o'clock are diminishing, and he feels altogether happier. The only question that now arises is whether the second ear (the left), which is almost closed, should be operated on."

The next case, that of Dr. W. L. M- of Waterford, brother of Dr. G. M- - operated on eight years ago, as above mentioned, is thus described by the patient himself:"W. L. M- a medical man, aged thirty-five, strong and healthy, has been all his life a great sea-bather. He has never had syphilis. In August, 1884, he first began to experience a disagreeable 'fulness' in the ears, most marked in the left; unaccompanied, however, by either pain or deafness. Thinking this was probably caused by the presence of wax, on Aug. 19th he syringed out the left ear with warm water, rendering it immediately very deaf. As during the next few days hearing was not recovered, he became uneasy; and on the 22nd he consulted Dr. Storey in Dublin, who diagnosed a large exostosis in each ear, with irritation and inflammation of the left meatus. A solution of nitrate of silver (ten grains to the ounce) having been applied daily, the patient on the evening of the 28 th recovered his hearing. Mr. Field, whom he saw in London on Sept. 22nd, confirmed Mr. Storey's diagnosis. The exostoses were then both of considerable size, that in the right ear being the larger; but as there was still ample room for the passage of sound, Mr. Field recommended him to report himself at intervals, so that the progress of the disease might be observed. For the next few weeks no inconvenience whatever was experienced. On Oct. 23rd, when Mr. Field was again consulted, there was evident, but still only very little, enlargement of the right exostosis, while that of the left was scarcely perceptible. On the occasion, however, of the next visit, on March 12th, 1885, although hearing had in' the interval continued perfect, and no distress or pain had been suffered, Mr. Field advised an operation without further delay, both exostoses having increased so much that an extremely constricted space remained for the admission of sound. The patient accordingly went home, and, having made the necessary arrangements for remaining in London, returned thither on March 24th. On the same day Mr. Field operated on both ears. The exhibition of chloroform, which lasted fifty-five minutes, was not followed by any sickness, pain, sleeplessness, or lack of appetite. There was, however, great deafness, and on the day after the operation healthy pus was discharged from both ears. On March 27th the patient was able to be up, and on the 30 th he called on Mr. Field in his own house. On April 16th whilst still very deaf he removed from London. On the day following the left meatus cleared up sufficiently to admit of distinct hearing for about three hours, the right improving in a less degree. During the next fortnight hearing was very variable, being sometimes perfect with the left ear for hours, at other times absent for days together." On the return of the writer of the above from Ireland, on May 8th, to see me again, I found the ears still somewhat swollen but presenting plenty of room for the passage of sound. The curious feature in this case is its exact resemblance in symptoms and in the gradual recovery of hearing by both ears to that of the brother, Dr. G. Malready alluded to.

My next instance of removal of aural exostosis is afforded by Mr. H. C. W-- of Ipswich, aged twrenty-five, who has furnished me with the subjoined account of himself previous to the operation:- "It was in May, 1881, that I first felt inconvenience in hearing, but my deafness, which was not total, passed off in some four weeks. In January, 1882, I gradually lost all use of my right ear; and during the end of February and early part of March I had much pain in it, which my doctor could not relieve. On the 28th of last month I called on Mr. Field, who told me the ear would require an operation. He gave me a lotion which almost immediately relieved my pain, and after applying this thrice a day for some three months my hearing returned. Subsequently, until December, 1884, I was able to hear perfectly, although conscious of something in the ear which prevented one from pulling it about with impunity. In that month I grew quite deaf; and in March, 1885, I began once more to suffer pain, which was very acute. When, on April 13th, I for the second time eonsulted Mr. Field, he pronounced an operation absolutely necessary, and this, on the 21st, was performed." It remains to be added that in this case the growth was very large, and, after the use of the drill, had to be broken up with bone forceps, ${ }^{2}$ in a manner similar to that described in THE LANCET, April 1st, 1882. The patient recovered well from the operation, which lasted sixty-five minutes. His hearing is now (May 10th) almost perfect, and in a few days he will return home.

A consideration of the above and other cases leads one to the following general conclusions with respect to ivory aural exostoses:-1. They are by no means necessarily associated with a rheumatic, gouty, or syphilitic diathesis. 2. Their causation can, with strong probability, be ascribed in many, if not in all, cases to some local irritation of the external auditory meatus, such as may be set up by habitual sea-bathing. 3 . They can be most efficiently treated only by drilling, which with proper precautions-notably the use of a pliant and not brittle steel guard to protect tire ear in the event of slipping of the drill-is a perfectly safe operation. 4. Their prompt removal is indicated in all cases where $(a)$ they hinder the elimination of secretions and discharges from the auditory canal; $(b)$ where they occasion pain by pressure on neighbouring structure; $(c)$ where they threaten completely to block the meatus, and so to deprive the patient partially or wholly of hearing.

Lower Seymour-street, W.

\section{THE BULL A OF PEMPHIGUS.}

$$
\text { Bx GEORGE THIN, M.D. }
$$

IT has been stated by Gibier ${ }^{1}$ that acute pemphigus is due to a parasite. The microbe of acute pemphigus, according to this author, presents a beaded appearance when fully developed, the elements being grouped in rows consisting of two to twenty joints. Development takes place from minute spherical bodies isolated or irregularly grouped, or contained in zoogloea. This organism was found in the liquid of the bullø, and in the urine of the patient who formed the subject of his investigation. In the liquid of the bullæ in a case of chronic pemphigus the same author found a few bacteria moving slowly (rares bactéries à mouvements lents).

In a well-marked case of pemphigus in which I have recently examined the fluid of the bullæ I was unable to discover any organism.

A tall strong man, aged fifty-two, who had always enjoyed good health, consulted me on February 3rd, 1885, on account of an eruption. He stated that two months previously he had a rigor, and that within the next two or three days several "bladders" appeared on his forehead. Others then came out on his chest, arms, and legs, and had continued to appear more or less ever since. I found his face, neck, temples, and ears the seats of a bullous eruption, which in the aggregate involved on the lower part on the face more than half the surface. There were also several bullæ on the chest, back, arms, and legs, some being full of clear serum, some collapsed, and some burst, leaving a red moist surface covered with folds of epidermis. His general health was

2 This was one of those cases which may be dealt with by the use of a chisel and hammer, or, as I prefer, by bone forceps, for the exostosis was not so hard as in the three cases just described. A large quantity of bone was removed from this patient's ear, and the ext,ernal auditory meatus afterwards looked large and open. The chisel I believe to be absolutely useless for ivory exostoses, and nothing but the drill, which makes only a small orifice (quite sufficient for the passage of sound), is of any service.

$\iota$ Annales de Dermatologie et de Syphilographie, vol. iii., p. 102. 
not perceptibly impaired. Fresh bullæ continued to come out, and I had an opportunity' of observing them in the earliest stage from their first appearance as minute, scarcely raised, vesicles, not much larger than a pin's head, with a central depression, and as large bullæ about two inches long, three-quarters of an inch broad, and about half an inch high.

On three separate occasions I examined the fluid of the bullæ microscopically without observing any organisms. I also prepared a number of cover glasses, on which the fluid was dried in the now familiar way, and the glasses, after being heated, were floated on solutions of aniline dyes and properly prepared for examination. No organisms were stained. In one preparation, examined fresh with the addition of a solution of gentian violet, some epidermic cells were found in the fluid, and to one of these micrococci were found adherent. The results of examining the fluid of the bullæ, both fresh and after being dried and stained, were thus, so far as organisms are concerned, entirely negative. A few white blood-corpuscles were found in the fluid. On Feb. 6th and 10th attempts were made to cultivate any organisms that might be present. The bullæ were opened largely with a purified lancet. A pure platinum wire was plunged into the depths of the bullæ, and tubes of sterilised gelatine-peptone meat infusion inoculated in the usual way. Two neutral, two alkaline, and one acid tube were thus inoculated and put aside at the ordinary temperature of my laboratory. Up to April 13th nothing had grown in the tubes, the gelatinised meat infusion having in the meantime become considerably shrunk.

These observations do not prove that no organisms are present in the fluid of the bulle of chronic pemphigus, but they tend to show that typical pemphigus may exist without the presence in the bullæe of organisms which can be put in evidence by the methods on which reliance is now placed. The organisms described by M. Gibier could not have been present in my case.

Queen Anne-street, W.

\section{A CASE OF LUMBAR COLOTOMY.}

\section{By WILLIAM DOBBIN, M.A., M.D., \&c.,} MEDICAL OFFICER, BAYMRIDGE DISPEYSARY.

ON March 24th, 1884, I visited a dispensary patient, Elizabeth $\mathrm{L}_{--}-$, aged seventy, married, residing at Tullyrain, near Banbridge. She was a tall woman, emaciated and cachectic-looking, but was not confined to bed. She stated that she was troubled with piles, and had suffered from painful defecation, attended with a bloody discharge for nearly three years. Lately her condition had become much aggravated as the constipation was more difficult to overcome, and there was much distressing tenesmus. examination $I$ found that there was a small tumour of stony hardness at the posterior margin of the anus, which doubtless had been formerly a pile, but was now a mass of scirrhus. The sphincter was a rigid circle which would admit only the tip of the finger, the introduction of which caused extreme distress. Per vaginam I found that a hard nodulated mass extended upwards for some four inches, projecting into the vagina in front and apparently encircling the lower end of the rectum. Avoiding mention of the dreaded word cancer, I told the patient that the only mode of relief was by an operation, but that it might be delayed for some time if she were careful to keep the stools soft by castor oil. An occasional opiate was administered when the pain was very severe, and I kept her under observation, visiting her from time to time when in the neighbourhood.

Matters went on without much marked change for nearly four months, when, on the 17 th of July, I received a message saying that she could not bear her condition any longer, and that she would submit to any operation for relief. As soon as possible I proceeded to her house accompanied by Dr. Smyth, J.P., and Dr. Tweedie of Banbridge, who kindly afforded me their valuable advice and assistance. They concurred in the diagnosis of malignant stricture of the rectum, and agreed that lumbar colotomy ought to be performed at once. Chloroform having been administered, the colon was opened in the left loin by Callisen's operation as modified by Mr. Bryant, all of whose directions in the various steps of the operation were carefully followed. Hardly a table- spoonful of blood was lost. Some difficulty was experienced in seizing the gut, as rather unexpectedly it was found to be empty. After the sutures were fastened the part was dressed with carbolised oil on lint, a pad of oakum was applied, and the whole secured by a binder. Ordered to have milk diet for a few days, and fifteen minims of tincture of opium in half an ounce of water every four hours.

July 18th.- The patient has passed a good night, and feels very comfortable. Pulse 80 ; tongue clean; skin cool; no pain or tenderness. Wound dressed; looking healthy Orderea five grains of compound ipecacuanha powder every four hours in place of the draught.-19th: Wound dressed. The patient feels very comfortable.--20th: Wound dressed. A good deal of flatus has passed through artificial anus, but no fæces. Flatulent distension complained of ; a linseed-meal and mustard poultice to be applied to abdomen. In addition to anodyne powders, to have a grain of quinine three times a day.-21st: Wound dressed. Since last visit there has been a free discharge of semi-fluid fæces through artificial anus; abdomen much less distended; some appetite for food; in good spirits. Compound ipecacuanha powder to be discontinued, except five grains at bedtime.--22nd: Wound dressed; free discharge of fæces continues; sutures removed; most of skin wound healed by first intention; opening in bowel firmly united to skin.-23rd: Wound dressed. Discharge of fæces has been enormous since the middle of the night; a good many scybala have passed.-24th: Wound dressed. Since last visit fæces have passed in large quantity, but have now ceased. She is clean and comfortable, and is in good spirits.-25th: Since last visit a small quantity of fæces passed per vaginam. This happened only once.

On July 28th, during the night, the patient's husband, who alone lived in the house with her, died suddenly in the bed beside her; and the poor creature, being dreadfully frightened, made her way in a half-dressed state to the house of a relative, who lived about half a mile off, for the purpose of seeking assistance. Fortunately, the journey did her no injury, although she fell several times. After the fatigue passed away she made a capital recovery. A pad of fine tow was kept constantly over the artificial anus, and was fastened in position by a binder. A new pad was applied after each action of the bowels, which took place usually once in the twenty-four hours. Under these circumstances the woman's health continued fairly satisfactory till the end of October, when a large abscess formed and discharged in the left hip. From this period she gradually became weaker and more cachectic, and finally sank on Nov. 24th, four months and seven days after the operation.

Remarks.-Surgical interference without doubt prolonged the life of this patient. It not only relieved her from painful and exhausting straining efforts at defecation, but retarded the progress of her malady by preventing the irritating passage of the freces over the diseased bowel. What is more important still, existence was rendered endurable and the woman was enabled to end her days in comparative comfort. After the first week she told me she was easier than she had been for two years, and that she was already more than compensated for submitting to the operation. Such a result is ample justification for operating, and I should have no hesitation in recommending colotomy in a similar case. The operation is not excessively difficult if Mr. Bryant's directions as given in his work on the Practice of Surgery are carefully attended to, and it is not more dangerous than herniotomy, if done in good time. There is no necessity for a patient the subject of artificial anus to wear any special appliance, since a pad of fine tow is quite sufficient. It is cleanly, cheap, and a fresh one can be put on whenever required. I have reported this case, occurring in the practice of a country surgeon, as it may encourage others similarly situated to carry out a serious operation even in the confined bedroom of a dispensary patient.

Banbridge, co. Down.

Dr. G. E. PAGET.-At the next quarterly meeting of the governors of Addenbrooke's Hospital, the LordLieutenant of the county will, on behalf of the governors, be asked to accept a bust of Dr. George Edward Paget, F.R.S., Regius Professor of Physic in the University of Cambridge, which has been provided by the subscriptions of a large number of persons, the list being headed by his Royal Highness the Prince of Wales and his Royal Highness Prince Edward of Wales. 